\title{
Corrosion and Erosion-Corrosion Processes of Metal-Matrix Composites in Slurry Conditions
}

\author{
J.F. Flores, A. Neville, N. Kapur, and A. Gnanavelu
}

(Submitted September 23, 2010; in revised form February 20, 2011)

\begin{abstract}
The corrosion and erosion-corrosion (EC) processes of four metal-matrix composites (MMCs) in a simulated cooling water environment have been assessed in this article. The MMCs consisted of two Ni-base and two Fe-base matrices alloyed with different concentrations of chromium, molybdenum, boron, silicon, and carbon; the matrices were reinforced with tungsten carbide (WC) particles. The corrosion behavior has been investigated using a combination of potentiostatic polarization and post-tests surface analysis. The EC processes were studied by in situ electrochemical techniques measuring the current density and corrosion potential response at different slurry temperatures and sand content. At static conditions it was found that as the temperature increased, there was a transition from a homogeneous corrosion of the matrix to an interfacial corrosion mechanism. The Ni-base MMCs showed a better corrosion resistance and interestingly a highly alloyed matrix did not significantly improved MMC's corrosion resistance. In the in situ EC tests, the Fe-base MMCs showed a constant increase in the current density at all sand contents. Whereas, significant changes were not observed in the Ni-base MMCs below $0.5 \mathrm{~g} / \mathrm{L}$. Although sand content had an effect on the monitored current density (the current increased as the sand content increased) this effect was less pronounced above $3 \mathrm{~g} / \mathrm{L}$.
\end{abstract}

Keywords corrosion testing, erosion-corrosion, metal-matrix composites, slurry transportation

\section{Introduction}

EC is a severe and complex degradation process in which mechanical and electrochemical events interact, causing material loss and component failure (Ref 1$)$. The total material loss results from the sum of the individual contributions of mechanical and electrochemical degradation components and an additional term knows as synergistic or additive effect (Ref 1,2$)$. Several industrial processes are negatively affected by EC. For instance, the oilsands extraction process (Ref 3-5), power generation (Ref 6), phosphoric acid production (Ref 7), metal and mineral extraction (Ref 8), acidic latching of industrial minerals such as copper silicates and phosphate rocks among others. In an EC process, the contribution of the erosion damage results from solid particles impacting the material surface at different angles and velocities; the erosion mechanism and damage extent depends on the material mechanical properties and impact conditions (Ref 9-11). For instance, ductile materials absorb the impact energy by elastic

J.F. Flores-Formerly at Institute of Engineering Thermofluids, Surfaces and Interfaces, School of Mechanical Engineering, University of Leeds, Woodhouse Ln., Leeds LS2 9JT, UK.

J.F. Flores, GE Global Research Center, One Research Circle CE2537, Schenectady, NY 12309; and A. Neville, N. Kapur, and A. Gnanavelu, Institute of Engineering Thermofluids, Surfaces and Interfaces, School of Mechanical Engineering, University of Leeds, Woodhouse Ln., Leeds LS2 9JT, UK. Contact e-mail: juanfcoflores@gmail.com. and plastic deformation, consequently craters, debris, and material lips are formed and progressively removed by subsequent impacts (Ref 12). On the other hand, brittle materials dissipate the impact energy by the formation and growth of microcracks and microfatigue; the microcracks networks merge fracturing the material and producing material loss (Ref 13).

Many studies have been carried out to understand the contributions of corrosion to the material degradation under EC conditions, for instance, some authors suggest that for active materials the work-hardened layer and the material debris formed by erosion, are removed by anodic dissolution (Ref 1$)$. In addition, the surface roughness is increased as a consequence of the plastic deformation enlarging the surface area exposed to EC. Furthermore, as studied by Xie et al. (Ref 14), the surface strain energy of a high carbon low alloy steel increases as a consequence of mechanical erosion. They concluded that high strain energies enhanced the anodic dissolution of the steel surface and moved its corrosion potential toward more active values (Ref 14). In passive materials the protective layer can be removed by solid particle impacts (Ref 15-18). There is a competition between depassivation and repassivation processes; if the surface is subjected to a continuous and severe erosion degradation and the layer is removed, the unprotected surface will be exposed to the aggressive media (Ref 15, 18).

For multiphase materials such as metal-matrix composites (MMCs) corrosion can preferentially dissolve the matrix phase and the hard phase-matrix interface (Ref 2,19). The severity of the selective dissolution depends on the matrix phase corrosion resistance, the presence of additional precipitates and differences in the corrosion electrochemical potential $\left(E_{\text {corr }}\right)$ of the matrix and the hard phase (Ref 20,21).

In terms of EC, Wentzel and Allen (Ref 22) studied the EC behavior of tungsten carbide (WC)-base hard metals with different matrices in a water-silica slurry ( $7 \%$ mass of solids) 
at $6.5 \mathrm{~m} / \mathrm{s}$. They used gravimetric and potentiodynamic techniques to evaluate the four different matrix compositions and they concluded that alloying pure $\mathrm{Co}$ and $\mathrm{Ni}$ matrices increased the erosion resistance of the hard metals. However, increasing the passivation of their matrices did not significantly improve their EC resistance (Ref 22).

Souza and Neville (Ref 23) studied the corrosion and EC behavior of WC-Co-Cr cermet coatings. The tests were carried out in a $3.5 \% \mathrm{NaCl}$ solution at $18{ }^{\circ} \mathrm{C}$ and two solids loadings $(0.2$ and $0.5 \mathrm{~g} / \mathrm{L})$. From their anodic polarization results, two breakdown potentials $\left(E_{\mathrm{b}}\right)$ were observed. They concluded that the first $E_{\mathrm{b}}$ was related to localize interfacial corrosion whereas; the second was attributed to pitting of the binder. They reported that the EC damage mechanisms were dominated by erosion and the corrosion current density $\left(i_{\text {corr }}\right)$ was significantly increased under EC conditions compared to that at static corrosion (Ref 23). Neville et al. (Ref 2) assessed the corrosion and EC of four Ni-base MMCs reinforced with different WC grains particles sizes. The testing solution simulated a recycle cooling water environment at 25 and $65{ }^{\circ} \mathrm{C}$ and the slurry sand content was $5 \mathrm{wt} . \%$. They reported little differences in the static corrosion behavior of the MMCs and they suggested that the corrosion degradation process started around Boron-rich phases embedded in the matrix. They concluded that under EC conditions at $65{ }^{\circ} \mathrm{C}$, corrosion significantly deteriorated the WC particles support from the matrix phase, increasing the total material loss compared to that at $20^{\circ} \mathrm{C}(\operatorname{Ref} 2)$. Chromium has been extensively used to improve the corrosion resistance of MMCs and therefore, erosion-corrosion (EC) performance (Ref 2-19). However, as previously mentioned (Ref 22) under very aggressive conditions, increasing the $\mathrm{Cr}$ content did not significantly increase the MMCs EC resistance. It is important to indicate that due to $\mathrm{Cr}$ toxicity there have been efforts to substitute it by other active protection methods (Ref 24).

In situ electrochemical studies under EC conditions have been carried out by several authors. For instance, $\mathrm{Hu}$ and Neville (Ref 15) studied the electrochemical response of stainless steels in liquid-solid impingement. They found a critical solid loading at which, the passive layer was dramatically deteriorated by particle impacts. Additions of solids to the testing solution (above the critical point) promoted a linear increase of the monitored current density (Ref 15). Guo et al. (Ref 1) studied the effect of sand concentration on the anodic current density of carbon steel. They found a linear relationship between sand concentration and anodic current density when the steel was tested in a rotating cylinder electrode (RCE) system at different sand concentrations (0-40 wt.\%). Zhou et al. (Ref 25) also used a RCE, potentiodynamic polarization and cathodic protection to analyze the synergy between erosion and corrosion on mild carbon steel. They observed that the anodic behavior of the steel was significantly affected by erodent additions (alumina) and rotating velocity. Finally, they concluded that corrosion did not have a significant effect on erosion in conditions of active dissolution and passive state (obtained polarizing the sample) (Ref 25). In previous studies published by the authors on the EC behavior of $\mathrm{Ni}_{\text {base }}$ (Ref 26) and $\mathrm{Fe}_{\text {base }}$ (Ref 27) MMCs, it was observed that in concentrated slurries, the anodic polarization behavior of the MMCs showed little change when the erosivity of the slurries, expressed as sand content, was increased above $10 \mathrm{~g} / \mathrm{L}$.

In this article, the electrochemical response under EC of WC-MMCs with different matrices composition is investigated. The aim of this work is to describe the overall effect that the sand content, matrix phase and the microstructural features have on the current density response of the MMCs. The MMCs were also exposed to different fluid temperatures to assess the influence of increasing the slurry corrosivity (increasing fluid temperature) on the MMCs electrochemical response.

\section{Experimental Procedure}

\subsection{Materials}

Four different MMCs [two nickel-base $\left(\mathrm{Ni}_{\text {base }}\right)$ and two iron-base $\left.\left(\mathrm{Fe}_{\text {base }}\right)\right]$ were analyzed in this study. The MMCs were obtained by mixing the WC reinforcing phase particles ( 65 wt. $\%$ ) and the matrix phase powders. The chemical composition of the matrix powders reinforced with WC particles is presented in Table 1 .

The $\mathrm{Ni}_{\text {base }}$ MMCs were obtained using two variations of $\mathrm{Ni}-\mathrm{Cr}$ (nickel-chromium) matrices, one with a lower concentration of alloying elements (WC-NiCrBSi) and one with additional alloying elements such as molybdenum (Mo) and tungsten (W), (WC-NiCrMoWB). The $\mathrm{Fe}_{\text {base }} \mathrm{MMCs}$ were developed using two variations of $\mathrm{Fe}-\mathrm{Cr}-\mathrm{C}$ alloys; one with a low concentration of $\mathrm{Cr}$ and $\mathrm{C}$ (WC-FeCr) and one with a higher concentration of alloying elements (WC-FeCrC). The matrix microhardness was measured using a $100 \mathrm{~g}$ load on the as-polished samples and the results are also presented in Table 1.

\subsection{Corrosion Behavior of the MMCs in Static Conditions}

A conventional three electrode electrochemical cell was used in the static corrosion and the in situ EC tests. A potassium chloride $(\mathrm{KCl})$ saturated $\mathrm{Ag} / \mathrm{AgCl}$ electrode and a platinum rod were used as reference and counter electrodes, respectively. The MMC was the working electrode and it was prepared by welding a conductive wire to square MMCs samples

Table 1 Chemical composition (wt.\%) of the hardfacing matrix powders and MMCs microhardness

\begin{tabular}{|c|c|c|c|c|c|c|c|c|c|c|}
\hline Material & Microhardness $\left(\mathrm{HV}_{100}\right)$ & $\mathbf{C}$ & B & $\mathbf{S i}$ & $\mathrm{Fe}$ & & $\mathrm{Cr}$ & $\mathrm{Ni}$ & Mo & $\mathbf{W}$ \\
\hline WC-NiCrMoWB & $1160 \pm 142$ & 0.32 & 2.89 & 4.57 & 3.77 & & 17.5 & $\mathrm{Bal}$ & 12.7 & $\sim 5$ \\
\hline WC-NiCrBSi & $834 \pm 64$ & 0.45 & 2.27 & 3.27 & 2.32 & & 12.44 & Bal & na & na \\
\hline Material & Microhardness $\left(\mathrm{HV}_{100}\right)$ & $\mathbf{C}$ & Mn & $\mathbf{S i}$ & & $\mathrm{Cr}$ & & Mo & $\mathbf{F e}$ & $\mathbf{S}$ \\
\hline WC-FeCrC & $1135 \pm 91$ & 2.8 & 0.6 & 0.6 & & 27.2 & & 0.5 & Bal & na \\
\hline $\mathrm{WC}-\mathrm{FeCr}$ & $1216 \pm 100$ & 0.007 & na & 0.5 & & 12.5 & & na & Bal & 0.01 \\
\hline na: not available & & & & & & & & & & \\
\hline
\end{tabular}


$\left(\sim 3.3 \mathrm{~cm}^{2}\right)$ and mounted using a nonconductive epoxy resin. For the potentiostatic test, the testing electrolyte had a concentration of $1000 \mathrm{ppm}$ of chloride and a $\mathrm{pH}$ of 8.5 adjusted by additions of $\mathrm{NaOH}$. The electrolyte temperature was increased from 20 to $70{ }^{\circ} \mathrm{C}$ at a rate of $0.66{ }^{\circ} \mathrm{C} / \mathrm{min}$. The potential was held constant at $30 \mathrm{mV}$ above the corrosion potential $\left(E_{\text {corr }}\right)$ and the current density $(i)$, measured in $\mu \mathrm{A} / \mathrm{cm}^{2}$, was plotted against the electrolyte temperature. Potentiostatic tests in static conditions were conducted to study the effects of temperature on the electrochemical response of the MMCs; the potential was chosen to reduce the damage experienced by the materials due to polarization. The Arrhenius plots and the apparent activation energies were obtained to assess changes in the corrosion process and to define the corrosion mechanisms. The corrosion tests in this investigation were carried out following the ASTM G3 and G5 standards guidelines (Ref 28, 29).

The corrosion mechanisms and surface degradation evolution were established by microscopic analysis of the MMCs surface after potentiostatic tests. The samples were immersed in the testing solution at 20,45 , and $65^{\circ} \mathrm{C}$ for $90 \mathrm{~min}$ under potentiostatic control at a potential of $0.03 \mathrm{~V}$ above the $E_{\text {corr }}$. The testing temperatures were selected to analyze the corrosion mechanism at low temperature $\left(20^{\circ} \mathrm{C}\right)$, a temperature slightly above the critical temperature according with the Arrhenius plots (as presented later in this article) and at $65^{\circ} \mathrm{C}$ for comparison purpose with previous studies carried out by the authors (Ref 26, 27).

\subsection{Electrochemical Behavior of the MMCs Under EC Conditions}

Potentiostatic tests were carried out in situ to establish the influence of sand content and slurry temperature on the electrochemical response of the MMCs under different EC conditions. The EC tests were carried out using a submerged jet impingement apparatus based on a previous design developed by $\mathrm{Zu}$ et al. (Ref 30); the main equipment characteristics have been described elsewhere (Ref 26).

The electrochemical cell arrangement and the testing solution were the same as for the static corrosion tests. The sand used in this study was Ottawa silica sand 50/70 and the particles size was in the range of $200-300 \mu \mathrm{m}$; for all tests the angle of impingement was $90^{\circ}$ and the velocity was $14 \mathrm{~m} / \mathrm{s}$. The influence of the sand content in the current response and $E_{\text {corr }}$ were analyzed in situ while the sand content was increased from 0 to $50 \mathrm{~g} / \mathrm{L}$ (static condition, solids-free flow, 0.03, 0.05, $0.1,0.2,0.5,1,2,3,10,25$, and $50 \mathrm{~g} / \mathrm{L}$ ) at temperatures of 20 and $65{ }^{\circ} \mathrm{C}$.

\section{Results}

\subsection{General Microstructural Aspects}

The MMCs studied in this article comprise a complex microstructure which consists of a reinforcing phase (WC) and several secondary phases (carbides, borides, silicides, and W-rich phases). A detailed analysis of the MMCs microstructure is not the main purpose of this research article, however, general information regarding the microstructural characterization of the MMCs has been published by the authors elsewhere (Ref 26, 27), additional structural and solidification studies are under investigation. Previous findings relevant to this research work are summarized as follows:

1. The microstructure of the WC-FeCrC MMC (Fig. 1a) consisted of WC reinforcing particles and W-rich secondary phases embedded in a Fe-rich matrix phase. The calculated
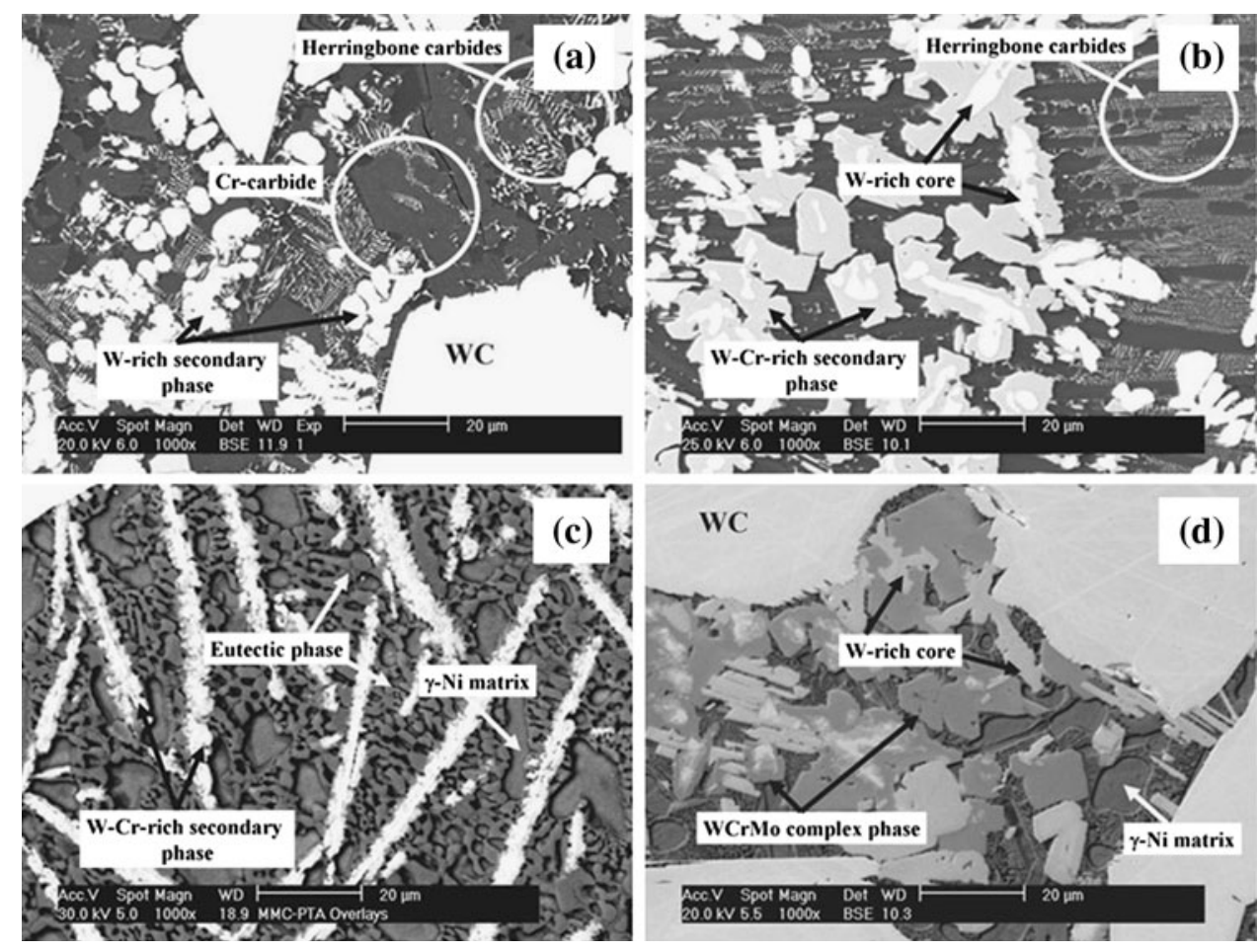

Fig. 1 Scanning electron micrographs showing general aspects of the MMCs microstructure: (a) WC-FeCrC, (b) WC-FeCr, (c) WC-NiCrBSi, and (d) WC-NiCrMoWB 
volume fractions of the MMC microstructural components were as follows: WC reinforcing particles, 39\%; W-rich secondary phases, $25 \%$; and the Fe-rich matrix phase covered $36 \%$ of the MMC microstructure. The secondary phases found in the WC-FeCrC MMC were mainly primary chromium carbides, herringbone carbides, and iron-tungsten carbides (Ref 31). The evolution of these secondary phases promoted the formation of Cr-depleted zones and chemically dissimilar sites around them.

2. The microstructure of the WC-FeCr MMC is shown in Fig. 1b). The calculated volume fractions of the $\mathrm{WC}-\mathrm{FeCr}$ MMC microstructural components were 33\% of the MMC was covered by the WC reinforcing particles, $33 \%$ by the W-rich secondary phases, and $35 \%$ by the Fe-rich matrix phase. The secondary phases formed in the WC-FeCr MMC were similar to those formed in the WC-FeCrC MMC. However, it was found that the iron-tungsten carbides in the former were larger than those found in the latter (Ref 31).

3. The microstructure of the WC-NiCrBSi MMC is shown in Fig. 1(c). The calculated volume fractions of the WC-NiCrBSi microstructural components were WC reinforcing particles, 56\%; W-rich secondary phases, 11\%; and Ni-rich matrix phase, 33\%. The WC-NiCrBSi matrix phase was composed of a globular $\gamma$-Ni structure and a eutectic mixture containing nickel borides and silicides. The elongated W-rich secondary phases in the microstructure of the WC-NiCrBSi MMC (Fig. 1c) were complex (W,Cr,Ni)-carbides (Ref 26, 31).

4. Finally, the WC-NiCrMoWB microstructure is shown in Fig. 1(d). It was calculated that $56 \%$ of its surface was covered by the WC particles, $24 \%$ by secondary phases, and $20 \%$ by the Ni-rich matrix. The WC-NiCrMoWB MMC secondary phases were also complex (W,Ni,Mo,Cr)-carbides. It was found that the Mo and other alloying elements available in the matrix powder, contributed to the formation of very large secondary phases therefore, those elements were scarce in solid solution in the matrix phase.

\subsection{Static Corrosion Behavior and Corrosion Mechanisms of the MMCs}

The potentiostatic scans of WC-FeCrC and WC-FeCr MMCs as temperature is increased are shown in Fig. 2(a). Both $\mathrm{Fe}_{\text {base }}$ MMCs exhibited a significant rise in the monitored current density with the WC-FeCr MMC, showing the highest $i$ at all temperatures. Interestingly, the $\mathrm{WC}-\mathrm{FeCr} \mathrm{MMC}$ showed the greater $i$ and the largest volume fraction of W-rich secondary phases. On the other hand as shown in Fig. 2(b), the $\mathrm{Ni}_{\text {base }}$ MMCs exhibited a significantly lower $i$ compared to the $\mathrm{Fe}_{\text {base }}$ MMCs (more than 10 times lower) and the WC-NiCrBSi MMC, showed the lowest $i$ over the entire temperature range.

An Arrhenius plot was used to assess the effect temperature has on the MMCs corrosion process. The plot was obtained by plotting the logarithmic value of the reaction rate $(i)$ versus the inverse of temperature. The apparent activation energies were obtained by solving the graphical form of the Arrhenius equation (Ref 32,33$)$ :

$k=A e^{-E_{\mathrm{a}}} / R T$,

where $k$ is the rate constant for the reaction, $A$ is a proportionality constant that varies from one reaction to another,
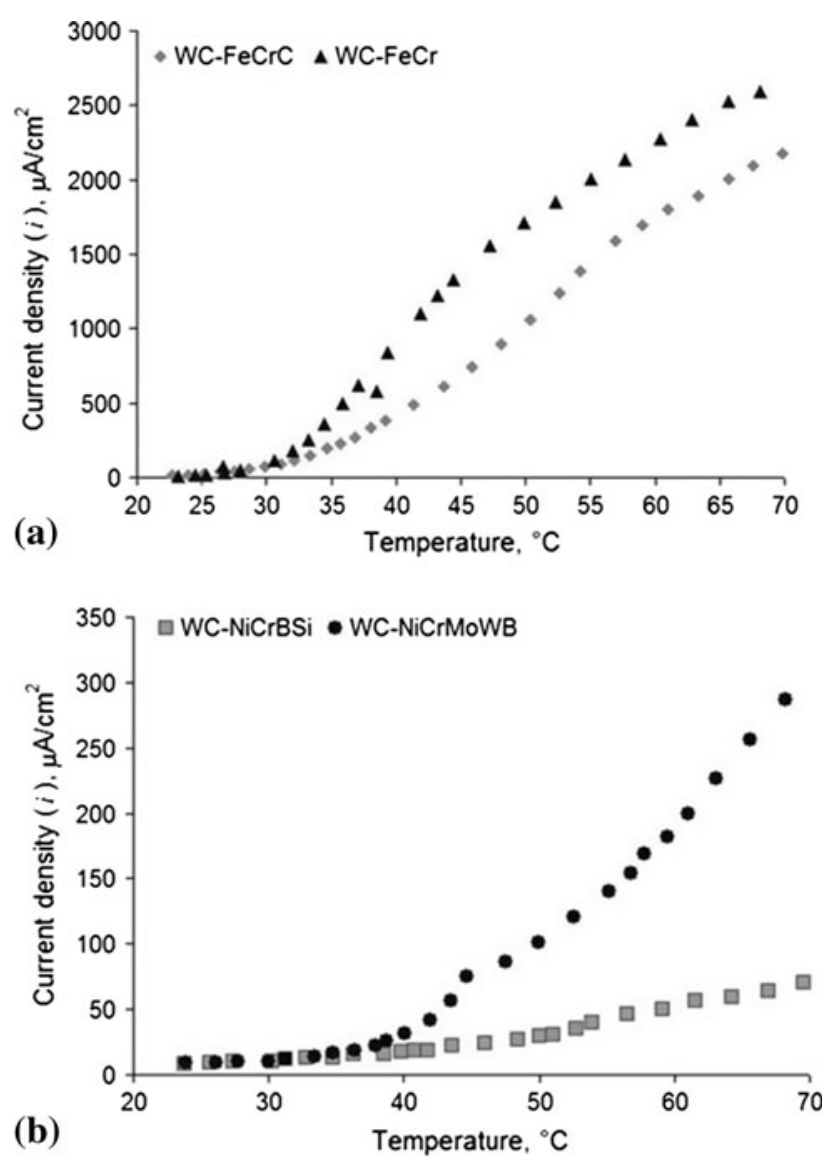

Fig. 2 Current density ( $i$ ) as a function of temperature for the MMCs: (a) WC-FeCrC and WC-FeCr MMCs and (b) WC-NiCrBSi and WC-NiCrMoWB MMCs

$E_{\mathrm{a}}$ is the apparent activation energy for the reaction, $R$ is the ideal gas constant in $\mathrm{J} / \mathrm{mol} \mathrm{K}$, and $T$ is the temperature in Kelvin. For the graphical form, the natural logarithm of both sides of the equation is incorporated in the Eq 1 as follows:

$\ln k=\ln A-E_{\mathrm{a}} / R T$

Then, Eq 2 is rearranged into a linear graphical format to determine the slope and $y$-intercept from the Arrhenius plot:

$\ln k=E_{\mathrm{a}} / R T[1 / T]+\ln A$

According to $\mathrm{Eq} 3$, the plot of $\ln k$ versus $1 / T$ gives a straight line with a slope of $-E_{\mathrm{a}} / R$ and the value of the $E_{\mathrm{a}}$ can be calculated.

The Arrhenius plots of $\mathrm{WC}-\mathrm{FeCrC}$ and $\mathrm{WC}-\mathrm{FeCr} \mathrm{MMCs}$ are shown in Fig. 3(a). They showed two distinct slopes (regimes), connected by a transition point (critical temperature, $T_{\mathrm{C}}$ ), where the rate control switched from one regime to the other. For the WC-FeCr MMC, regime I $\left(T<36{ }^{\circ} \mathrm{C}\right)$ has a calculated $E_{\mathrm{a}}$ of $232 \pm 15 \mathrm{~kJ} / \mathrm{mol}$ whereas, for the WC-FeCrC $\mathrm{MMC}$, regime I $\left(T<39{ }^{\circ} \mathrm{C}\right)$ has a calculated $E_{\mathrm{a}} 155 \pm 3 \mathrm{~kJ} / \mathrm{mol}$. Finally, a lower $E_{\mathrm{a}}$ was calculated in regime II $\left(T>T_{\mathrm{C}}\right)$ for both $\mathrm{Fe}_{\text {base }} \mathrm{MMCs}$. The $E_{\mathrm{a}}$ of the WC-FeCr MMC was reduced to $30.6 \pm 3.9$ and $45 \pm 1.9 \mathrm{~kJ} / \mathrm{mol}$ for the $\mathrm{WC}-\mathrm{FeCrC} \mathrm{MMC}$. Note that the testing temperature range for the potentiostatic test was from 20 to $70{ }^{\circ} \mathrm{C}$. Therefore, the lower temperature of regime I was $20^{\circ} \mathrm{C}$ and the higher temperature of regime II was $70{ }^{\circ} \mathrm{C}$. 

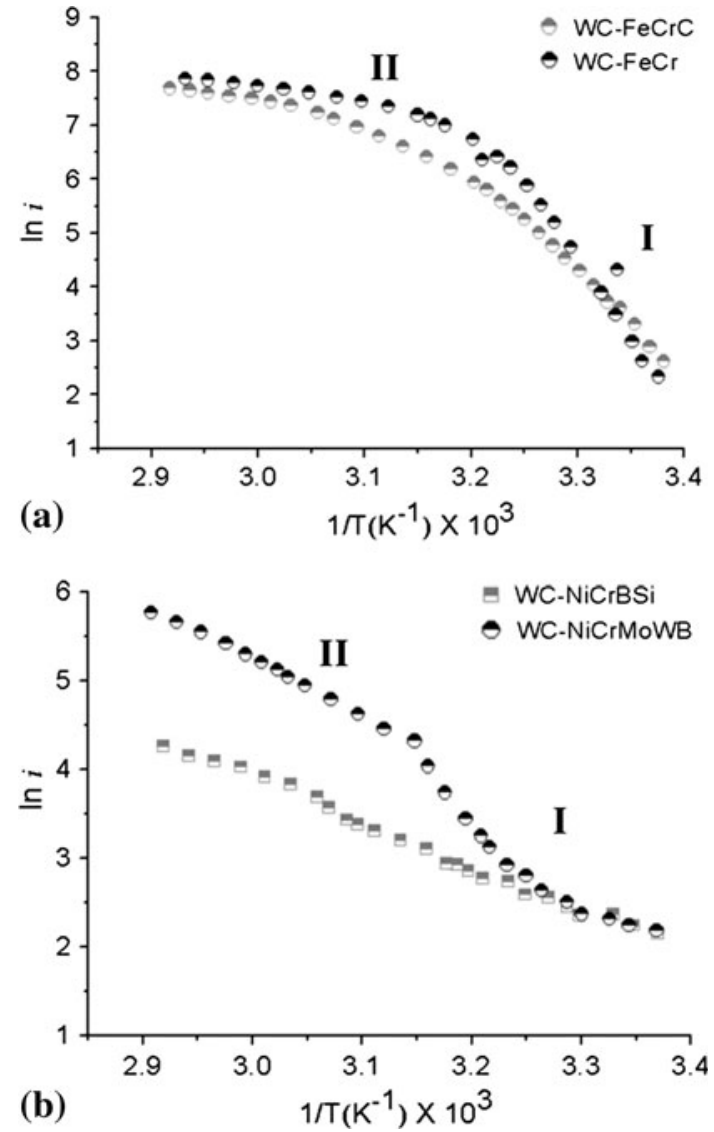

Fig. 3 Arrhenius plot of for the potentiostatic tests of the MMCs: (a) $\mathrm{WC}-\mathrm{FeCrC}$ and $\mathrm{WC}-\mathrm{FeCr} \mathrm{MMCs}$, (b) WC-NiCrBSi and WC-NiCrMoWB MMCs
Remarkable differences were observed in the corrosion behavior of the $\mathrm{Ni}_{\text {base }}$ MMCs as can be seen in Fig. 3(b). The WC-NiCrBSi MMC showed a more linear Arrhenius plot compared to the rest of the MMCs, the values of the control rate (ln $i$ ) were also significantly lower and the calculated $E_{\mathrm{a}}$ was in the range between 37 and $45 \mathrm{~kJ} / \mathrm{mol}$. Finally, for the WC-NiCrMoWB MMC, $T_{\mathrm{C}}$ was between 43 and $45{ }^{\circ} \mathrm{C}$ and the calculated $E_{\mathrm{a}}$ was $77 \pm 7 \mathrm{~kJ} / \mathrm{mol}$ in regime I and $53 \pm 3 \mathrm{~kJ} / \mathrm{mol}$ in regime II.

\subsection{Surface Analysis After the Potentiostatic Tests}

The surface of the MMCs was analyzed after the potentiostatic tests at three different temperatures; at $20{ }^{\circ} \mathrm{C}$ to study the corrosion mechanisms in regime I far from $T_{\mathrm{C}}$, at $45{ }^{\circ} \mathrm{C}$ to assess the microstructural degradation slightly above $T_{\mathrm{C}}$, and at $65{ }^{\circ} \mathrm{C}$ to elucidate if there is any change in the MMCs corrosion mechanisms in regime II.

Figure 4 shows the optical micrographs of the MMCs surfaces after the potentiostatic tests at $20^{\circ} \mathrm{C}$. First, the $\mathrm{Fe}_{\text {base }}$ MMCs (Fig. 4a, b) seem to be more affected by corrosion attack than the $\mathrm{Ni}_{\text {base }}$ MMCs (Fig. 4c, d) for instance, all the microstructural features (secondary phases, matrix, and interface regions) were clearly revealed in the $\mathrm{Fe}_{\text {base }} \mathrm{MMCs}$. It can be observed that in the WC-NiCrBSi MMC (Fig. 4c) and the WC-NiCrMoWB MMC (Fig. 4d), the eutectic was the most affected phase whereas, the integrity of the WC grains and the majority of the secondary phases were not significantly degraded.

Shown in Fig. 5, after the potentiostatic tests at $45{ }^{\circ} \mathrm{C}$ (slightly above $T_{\mathrm{C}}$ ) the MMCs presented a more pronounced preferential corrosion attack. Voids and extensive interfacial corrosion were observed on the WC-FeCrC MMC (Fig. 5a) and the WC-FeCr MMC (Fig. 5b) and the reinforcing phases matrix
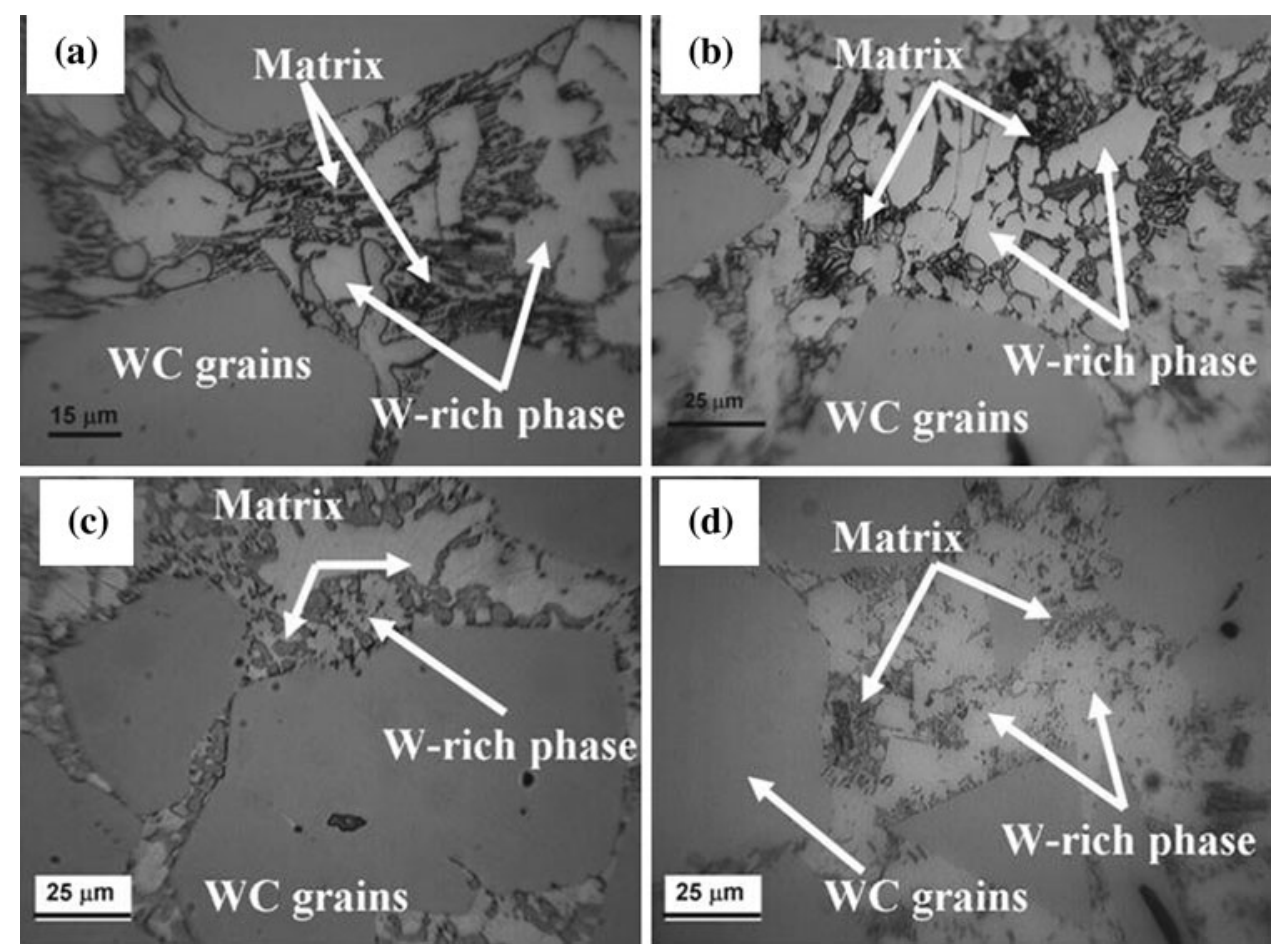

Fig. 4 Optical micrograph showings the surface analysis of the MMCs after potentiostatic tests at $20{ }^{\circ} \mathrm{C}$ : (a) $\mathrm{WC}-\mathrm{FeCr}$, (b) $\mathrm{WC}-\mathrm{FeCrC}$, (c) WC-NiCrBSi, and (d) WC-NiCrMoWB 

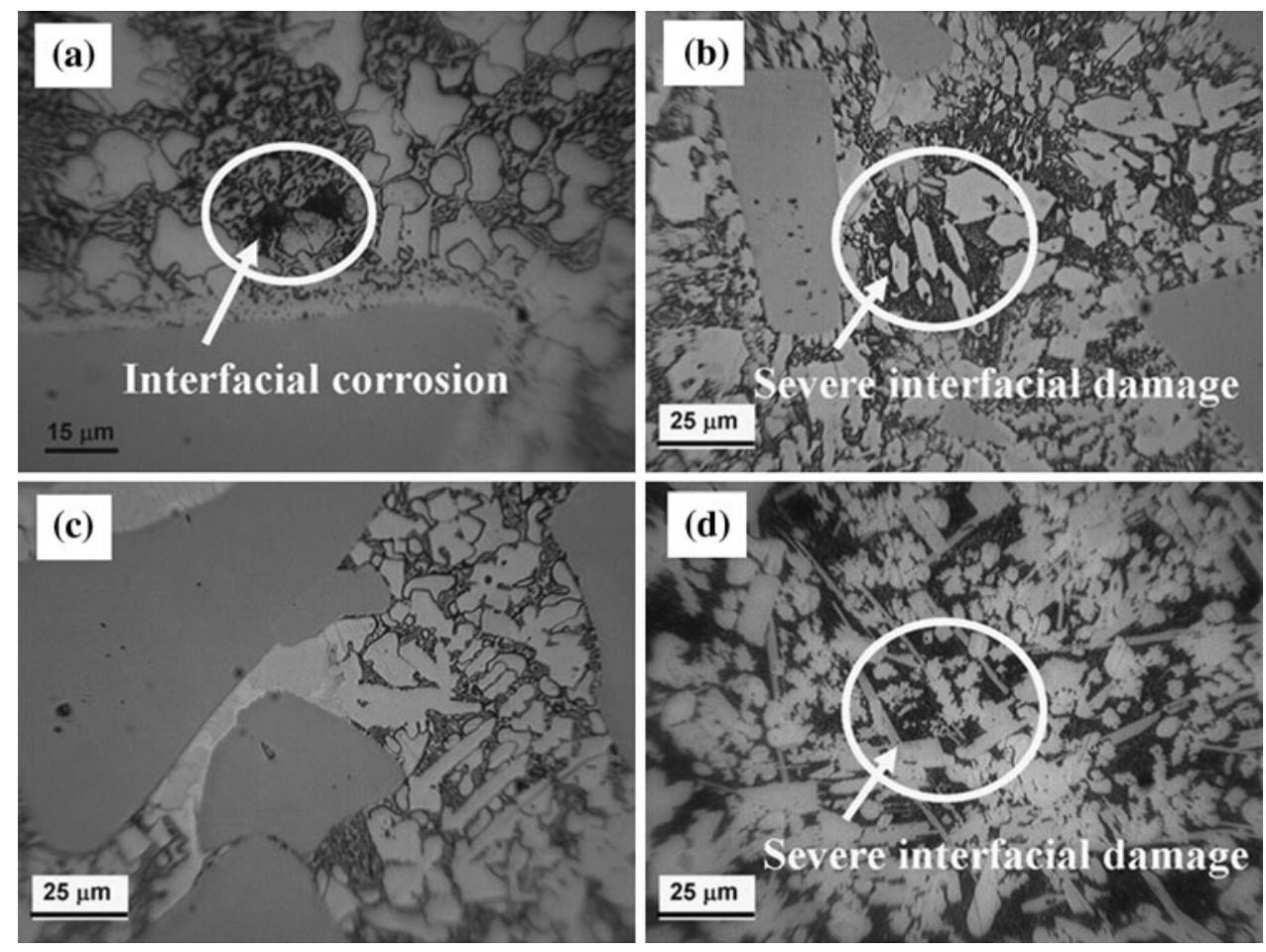

Fig. 5 Optical micrograph showings the surface analysis of the MMCs after potentiostatic tests at $45{ }^{\circ} \mathrm{C}$ : (a) $\mathrm{WC}-\mathrm{FeCr}$, (b) $\mathrm{WC}-\mathrm{FeCrC}$, (c) WC-NiCrBSi, and (d) WC-NiCrMoWB
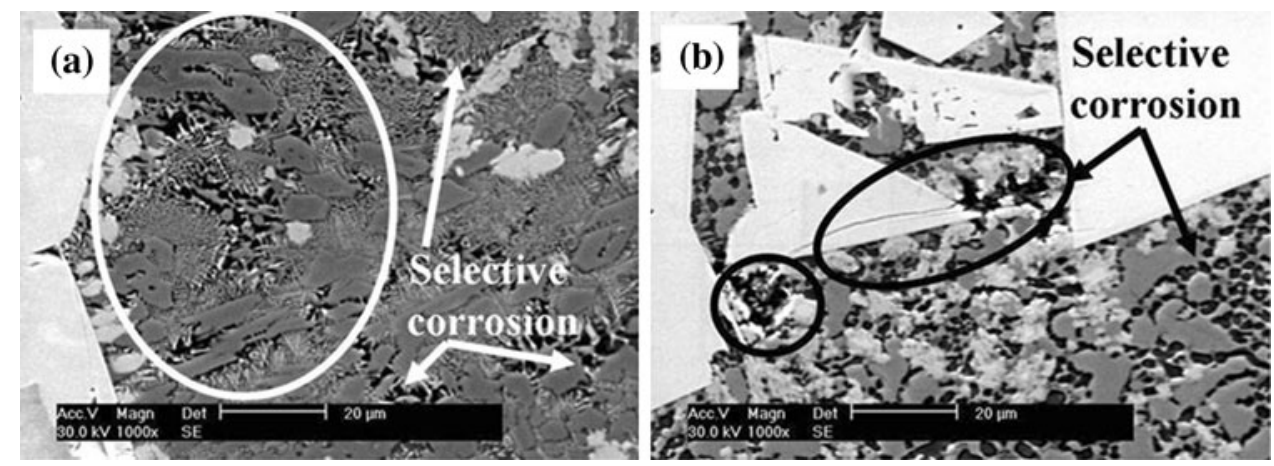

Fig. 6 Scanning electron micrographs showing signs of interface degradation on the surface of the WC-FeCrC MMC: (a) and the WC-NiCrBSi MMC (b) after potentiostatic test at $65{ }^{\circ} \mathrm{C}$

support was deteriorated. For the WC-NiCrMoWB MMC, the preferential corrosion attack mechanism was dramatically more pronounced at $T_{\mathrm{C}}$ (Fig. $4 \mathrm{~d}$ ) than it was at $20{ }^{\circ} \mathrm{C}$ (Fig. $5 \mathrm{~d}$ ). Similar behavior was observed in the WC-NiCrBSi MMC as in Fig. 5(c) nevertheless, the preferential attack was less extensive because the volume fraction of secondary phases was smaller.

As the electrolyte temperature was increased the extent of the preferentially attacked zones was enlarged and the number of voids and "microcrevice-like" sites were increased in all the MMCs. For instance, Fig. 6(a) shows the surface of the WC$\mathrm{FeCrC} \mathrm{MMC}$ after the potentiostatic test at $65^{\circ} \mathrm{C}$ (regime II) where a reinforcing phase skeleton can be observed and voids around some secondary phases were formed. A similar degradation process was observed in the WC-NiCrBSi MMC as shown Fig. 6(b).
There was a correlation between the enlargement of the MMCs preferential corrosion damage and the changes in the Arrhenius plot linearity. In regime I, there was temperature dependence in the reaction rate but not in the $E_{\mathrm{a}}$ therefore, is possible that the process was dominated by a more homogeneous corrosion process in the eutectic and interfacial zones, which seemed to require higher activation energy to take place below $T_{\mathrm{C}}$. Once $T_{\mathrm{C}}$ is reached, some of the preferentially attacked zones were further degraded to form voids and microcrevice-like sites promoting an autocatalytic and more heterogeneous process. Apparently, this change in surface coverage of more reactive sites promoted a corrosion mechanism which required a significantly lower $E_{\mathrm{a}}$ to proceed and increased the rate of reaction (lower slope). Note that the WC-NiCrBSi MMC has a smaller volume fraction of secondary phases thus, less sites where preferential attack can progress. 
Its microstructure was less affected by corrosion and showed a more linear Arrhenius plot therefore, temperature dependence reaction rate.

\subsection{Effects of Sand Content and Temperature on the Anodic Current Density and $E_{\text {corr }}$ Response}

Figure 7 shows current density measurements made on the MMCs at different sand content exposed to the high energy slurry. The values were recorded while progressively adding sand at 5-min interval from 0 to $50 \mathrm{~g} / \mathrm{L}$. It was observed that the $\mathrm{Fe}_{\text {base }} \mathrm{MMCs}$ showed similarities on their electrochemical response under EC conditions.

For instance:

1. Both $F_{\text {base }}$ MMCs showed current peaks at every sand loading (even at $0.03 \mathrm{~g} / \mathrm{L}$ ) and $i$ increased continuously during the 5-min interval (expanded zone in Fig. 7a).

2. Initially, the WC-FeCrC MMC showed higher $i$ values, however, above $10 \mathrm{~g} / \mathrm{L}$, the differences were significantly reduced.

3. When the slurry pump was switched-off, the $i$ recorded at static conditions, showed a pronounced decay reaching the values exhibited in the transition between 2 and $3 \mathrm{~g} / \mathrm{L}$.
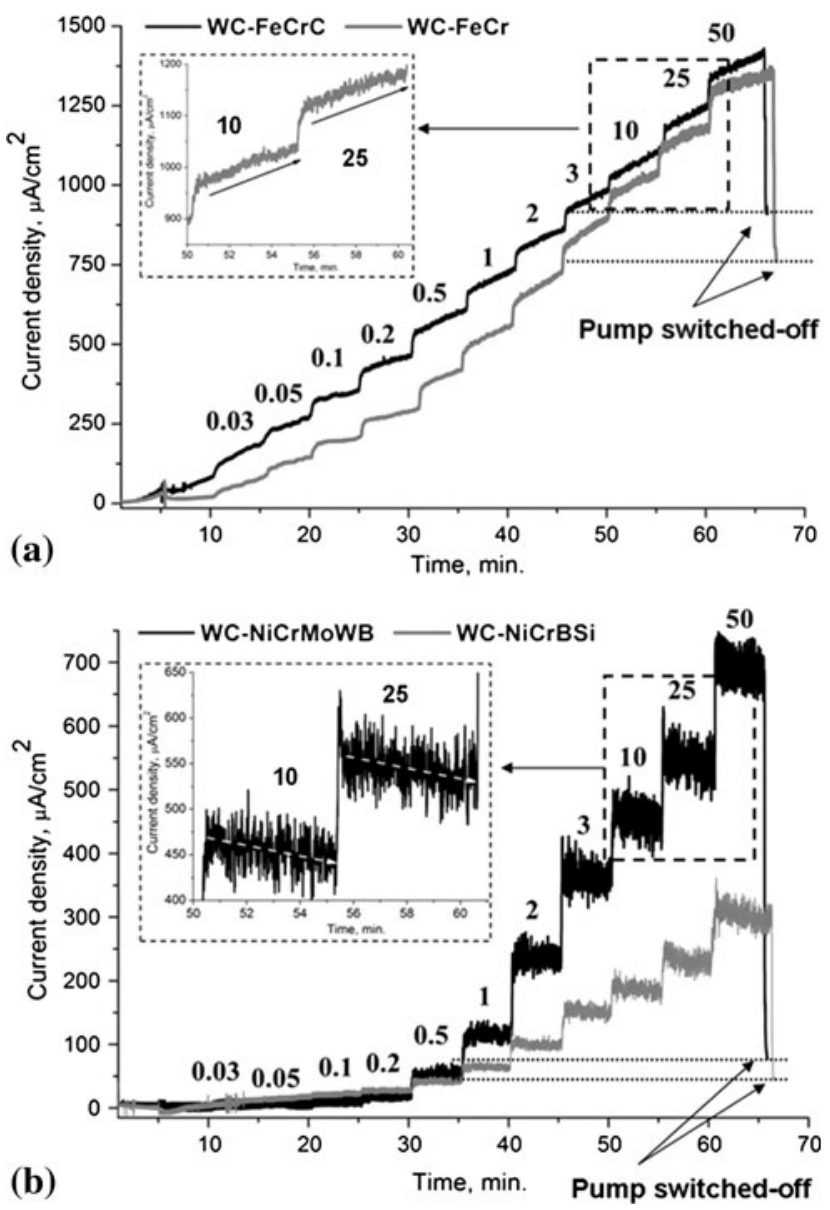

Fig. 7 In situ potentiostatic scan showing the effect of sand content on the electrochemical response of the MMCs under different $\mathrm{EC}$ conditions at $14 \mathrm{~m} / \mathrm{s}$ and $20{ }^{\circ} \mathrm{C}$ : (a) $\mathrm{WC}-\mathrm{FeCrC}$ and $\mathrm{WC}-\mathrm{FeCr}$, (b) WC-NiCrBSi and WC-NiCrMoWB. The sand content values are expressed in $\mathrm{g} / \mathrm{L}$
The following observations emerged from the analysis of the potentiostatic scans of the $\mathrm{Ni}_{\text {base }}$ MMCs (Fig. 7b):

1. The $i$ showed a relatively steady behavior below $1 \mathrm{~g} / \mathrm{L}$.

2. A small current peak was observed at $0.5 \mathrm{~g} / \mathrm{L}$ on both $\mathrm{Ni}_{\text {base }} \mathrm{MMCs}$, but unlike the $\mathrm{Fe}_{\text {base }} \mathrm{MMCs}$, the current density remains steady during the 5-min period.

3. Pronounced current peaks were detected between 2 and $3 \mathrm{~g} / \mathrm{L}$ with the WC-NiCrMoWB MMC showing higher $i$ value compared to the WC-NiCrBSi MMC.

4. From $3 \mathrm{~g} / \mathrm{L}$ and onwards, the current peak was not followed by steady behavior but, by a slightly decrease in the current density values (expanded region Fig. 7b).

Figure 8 shows the $E_{\text {corr }}$ of the MMCs as a function of the sand content at $20{ }^{\circ} \mathrm{C}$. The information obtained from the $E_{\text {corr }}$ versus time plot of the $\mathrm{WC}-\mathrm{FeCr}$ and $\mathrm{WC}-\mathrm{FeCrC} \mathrm{MMCs}$ is summarized as follows:

1. A shift in the negative direction of the $E_{\text {corr }}$ in static conditions (from 0 to $5 \mathrm{~min}$ ) was interrupted under solidsfree conditions (from 5 to $10 \mathrm{~min}$ ).

2. The $E_{\text {corr }}$ exhibited by the $\mathrm{Fe}_{\text {base }}$ MMCs started to overlap from $0.1 \mathrm{~g} / \mathrm{L}$ sand concentration and onward.

3. There was a correlation between increments in the current density (Fig. 7a) and the shift in the negative direction of the $E_{\text {corr }}$ (Fig. 8a).

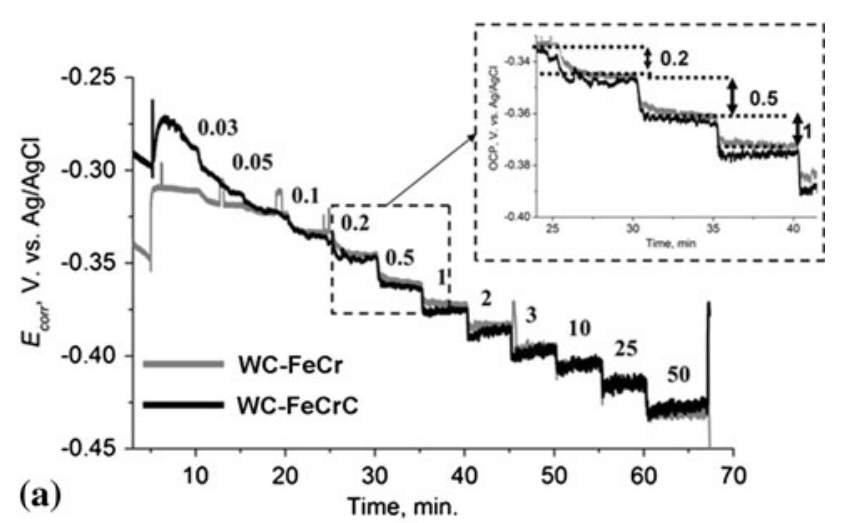

(b)

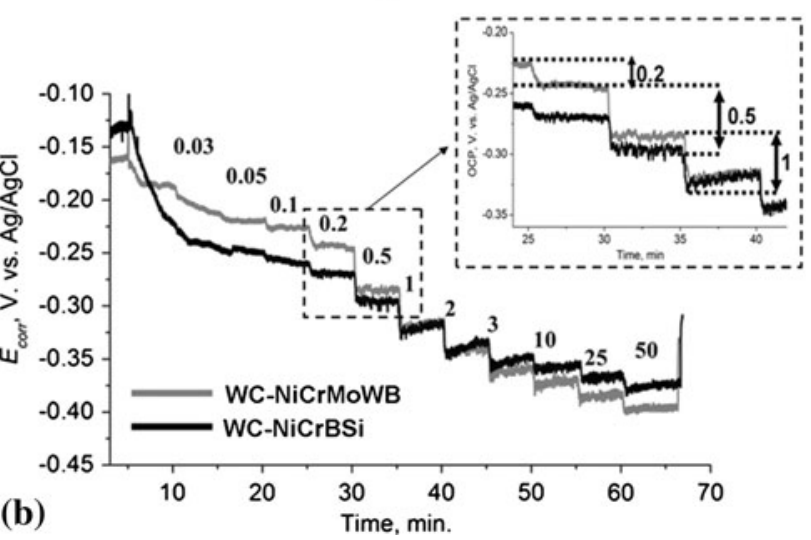

Fig. 8 In situ potentiostatic scan showing the effect of sand content on the $E_{\text {corr }}$ of the MMCs under different EC conditions at $14 \mathrm{~m} / \mathrm{s}$ and $20^{\circ} \mathrm{C}$ : (a) WC-FeCrC and WC-FeCr, (b) WC-NiCrBSi and WC-NiCrMoWB. The sand content values are expressed in $\mathrm{g} / \mathrm{L}$ 
The information obtained from the $E_{\text {corr }}$ versus time of the WC-NiCrBSi and WC-NiCrMoWB MMCs is summarized as follows:

1. The $E_{\text {corr }}$ showed a significant shift in the negative direction under solids-free conditions (Fig. 8b).

2. The shifts in the negative direction while adding more sand to the slurry were more pronounced from 0.5 to $10 \mathrm{~g} / \mathrm{L}$ (expanded region, Fig. 8b).

3. Above $2 \mathrm{~g} / \mathrm{L}$, the WC-NiCrBSi MMC showed a nobler $E_{\text {corr }}$ and ennoblement was observed at sand contents from 2 to $50 \mathrm{~g} / \mathrm{L}$.

The mean value of the logarithm of the current density as a function of the sand content at $20{ }^{\circ} \mathrm{C}$ is presented in Fig. 9(a). Note that there was a breaking point between 2 and $3 \mathrm{~g} / \mathrm{L}$ at which, the current density increment rate felt dramatically. Although sand content had an effect on $i$ (the current was increased as the sand content was increased) this effect was less pronounced above $3 \mathrm{~g} / \mathrm{L}$. The correlation coefficient $\left(R^{2}\right)$ values were greater for the $\mathrm{Fe}_{\text {base }} \mathrm{MMCs}$ perhaps because the $\mathrm{Ni}_{\text {base }}$ MMC showed very low $i$ at sand contents below $1 \mathrm{~g} / \mathrm{L}$ (Fig. 7b).

The effects of the temperature in the electrochemical response of the one $\mathrm{Fe}_{\text {base }} \mathrm{MMC}$ (WC-FeCr) and one $\mathrm{Ni}_{\text {base }} \mathrm{MMC}$ (WC-NiCrMoWB MMC) as a function of the sand content is presented in Fig. 9(b). It was clear that the slurry temperature considerably affected the electrochemical response of the MMCs and at $65{ }^{\circ} \mathrm{C}$ the materials showed significantly higher current density compared to that monitored at $20^{\circ} \mathrm{C}$ as expected. Nevertheless, it was observed that the critical sand content range still was between 2 and $3 \mathrm{~g} / \mathrm{L}$ supporting the fact that, above this range, the current density increase rate felt dramatically.

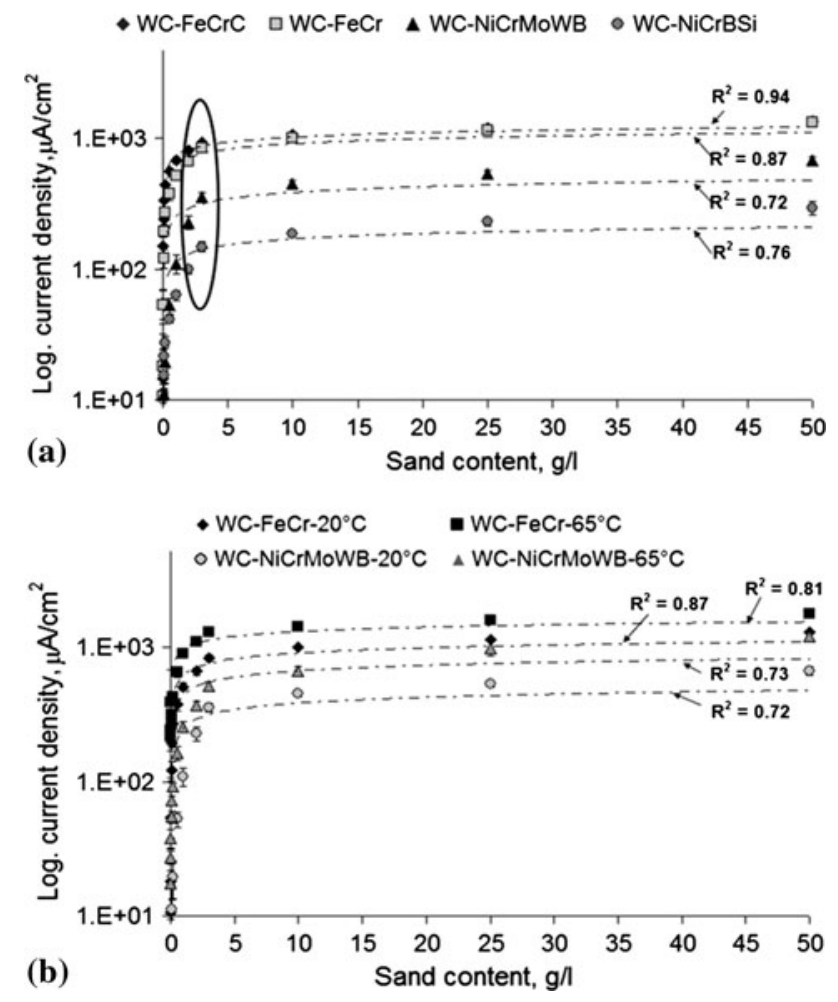

Fig. 9 Mean value of current density as a function of sand content and temperature at $14 \mathrm{~m} / \mathrm{s}$ : (a) $20{ }^{\circ} \mathrm{C}$ and (b) $65^{\circ} \mathrm{C}$

\section{Discussion}

\subsection{Corrosion Behavior and Degradation Mechanisms of the MMCs}

The MMCs studied in this research work presented a multiphase microstructure which, as observed in Fig. 1, consisted of at least three main components: a reinforcing phase (WC) embedded in a matrix phase ( $\mathrm{FeCr}, \mathrm{FeCrC}$, $\mathrm{NiCrBSi}$, and NiCrMoWB) and additional secondary phases. The formation of the secondary phases depends on the dissolution of the WC particles, the amount of alloying elements available in the matrix and the deposition process (Ref 9, 34). If a lower concentration of W, C, and other alloying elements (such as $\mathrm{Cr}, \mathrm{Mo}, \mathrm{B}$, and $\mathrm{Si}$ ) is available during the solidification of the MMCs, a smaller volume fraction of secondary phases can be formed (Ref 35 ). The large concentration of these phases in the WC-NiCrMoWB MMC can be explained by its highly alloyed matrix phase.

There was a correlation between the anodic current monitored at static conditions (Fig. 2) and the microstructure of the MMCs. For instance, the $\mathrm{Fe}_{\text {base }} \mathrm{MMC}$ showed the lower corrosion resistance since they presented the higher $i$ compared with the WC-NiCrBSi and WC-NiCrMoWB MMCs. Differences in $i$ between both $\mathrm{Fe}_{\text {base }}$ MMCs can be explained by the larger fraction of secondary phases in the matrix of the $\mathrm{WC}-\mathrm{FeCr} \mathrm{MMC}$ and the presence of a preferential dissolution process affecting the interfacial zones. The WC-NiCrMoWB MMC also showed a higher $i$ compared to the WC-NiCrBSi MMC especially above $T_{\mathrm{C}}$ (Fig. 2b).

Changes in the corrosion extent and control rate can be explained by analyzing the Arrhenius plots (Fig. 3a, b) and the surface of the MMCs after the potentiostatic tests (Fig. 4-6). For instance, two slopes were observed in the Arrhenius plot of the WC-FeCr and WC-FeCrC MMCs (Fig. 3a). The change in $E_{\mathrm{a}}$ in regime II indicates that less energy was required to proceed with the corrosion process (electrochemical reaction).

The presence of a catalytic process to accelerate the degradation of the MMCs as the temperature is increased is a possibility. For instance, a change toward lower $E_{\mathrm{a}}$ with increasing temperature is linked to a change in the ratedetermining mechanism. In chemical reactions (Ref 36-40), the presence of a catalyst considerably increases the rate control and decreases $E_{\mathrm{a}}$. For example, in their study of the atmospheric corrosion kinetics of iron and zinc, Cai et al., reported a reduction of $E_{\mathrm{a}}$ for corrosion of iron exposed to a sulfur dioxide atmosphere. They discussed that the oxidation of absorbed sulfite, $\mathrm{S}(\mathrm{IV})$, to sulfate, $\mathrm{S}(\mathrm{VI})$, was catalyzed by the Fe(II)/ $\mathrm{Fe}$ (III) redox couple. They concluded that the $E_{\mathrm{a}}$ fell as the ferrous and ferric species became available to promote the catalytic reaction (Ref 41).

Although, the $E_{\text {a }}$ shown in regime I by the $\mathrm{Fe}_{\text {base }}$ MMCs falls in the range of a activation control reaction $(>50 \mathrm{~kJ} / \mathrm{mol})$ (Ref 38), they are much higher than those reported for the anodic dissolution of mild steel in seawater $(60 \mathrm{~kJ} / \mathrm{mol})$ (Ref 39), corrosion of chromium in acid environments $(\sim 67 \mathrm{~kJ} / \mathrm{mol})$ (Ref 40$)$, or atmospheric corrosion of steel $(115-170 \mathrm{~kJ} / \mathrm{mol})(\operatorname{Ref} 41)$. A possible explanation to the high $E_{\mathrm{a}}$ in regime $\mathrm{I}$ is more than one electrochemical and chemical reactions are taking place simultaneously on the $\mathrm{Fe}_{\text {base }} \mathrm{MMCs}$ surface. Therefore, the calculated $E_{\mathrm{a}}$ represents the global degradation mechanism rather than a single electrochemical or chemical reaction. 
Interestingly, the $E_{\mathrm{a}}$ of the $\mathrm{Ni}_{\text {base }} \mathrm{MMCs}$ in regime I was similar to that calculated by Grigorev et al. (Ref 42) for the anodic dissolution of nickel in acid solutions in the presence of chloride ions. They reported a $E_{\mathrm{a}}$ equal to $57.4 \mathrm{~kJ} / \mathrm{mol}$, slightly above $E_{\mathrm{a}}$ calculated for the WC-NiCrMoWB MMC $(53 \mathrm{~kJ} / \mathrm{mol})$ or that one calculated for the WC-NiCrBSi MMC $(45 \mathrm{~kJ} / \mathrm{mol})$. Therefore, it is possible that for the $\mathrm{Ni}_{\text {base }}$ MMCs, the homogeneous dissolution of the Ni-rich eutectic phase was the ratedetermining mechanisms in regime I. It is proposed that once $T_{\mathrm{C}}$ was reached, a considerable number of more reactive sites (voids, microcrevice-like, severe interface attack among others) were formed. These sites catalyzed the corrosion process therefore reduced the $E_{\mathrm{a}}$. Considering the aforementioned, a schematic representation of the MMCs corrosion mechanisms based on the existence of a selective degradation process, supported by the Arrhenius plots and surface analysis, is shown in Fig. 10.

The structure of the MMCs before the potentiostatic tests is sketched in Fig. 10(a). The interfacial zones are starved of carbide-forming alloying elements such as $\mathrm{Cr}$ and $\mathrm{W}$ and are more susceptible to corrosion attack than the relatively chemically inert hard phase (WC and secondary phases). Furthermore, the presence of different microstructural components facilitated the development of microgalvanic cells as studied by others. For instance, Sutthiruangwong et al. (Ref 43) studied the corrosion behavior of Co-based cemented carbides and indicated that the corrosion potential $\left(E_{\text {corr }}\right)$ of the WC was approximately $0.14 \mathrm{~V}$ versus $\mathrm{Ag} / \mathrm{AgCl}$ which is considerably more noble than the $E_{\text {corr }}$ of Fe-rich and Ni-rich alloys $(-0.36$ and $-0.21 \mathrm{~V}$ versus $\mathrm{Ag} / \mathrm{AgCl}$, respectively) (Ref 9). Neville et al. (Ref 44), Zhan et al. (Ref 45), and Cooper et al. (Ref 20) analyzed the corrosion behavior of multiphase materials. They concluded that differences in $E_{\text {corr }}$ between the microstructural constituents of multiphase materials act as a driving force which favors the selective corrosion process (Ref 20, 44, 45).

When the temperature reached $T_{\mathrm{C}}$ the selective attack was deeper and voids (as those observed in Fig. 6a) and microcrevice sites were formed. The autocatalytic nature of this corrosion mechanism aggravated the structural degradation of the MMCs. It was clear that the smaller volume fraction of secondary phases in the matrix phase of the WC-NiCrBSi MMCs contributed to its better corrosion performance (lower current density values) and to retard or attenuate the initiation of selective attack (less pronounced change in the Arrhenius plot).

\subsection{Electrochemical Behavior Under EC Conditions}

The anodic current density of the MMCs in this investigation was monitored while increasing the sand content in the testing slurry. The $\mathrm{WC}-\mathrm{FeCr}$ and $\mathrm{WC}-\mathrm{FeCrC}$ MMCs showed a continuous increase of $i$ at all sand contents, indicating that even at the lowest value $(0.03 \mathrm{~g} / \mathrm{L})$, the electrochemical response of the $\mathrm{Fe}_{\text {base }} \mathrm{MMCs}$ surface was affected by erosion. Although in the Arrhenius plot the change in the slope was in a temperature range between 36 and $39^{\circ} \mathrm{C}$ (Fig. 3b), the initial measurements showed very high $i$ as shown in Fig. 2(a), which demonstrates the poor corrosion resistance of the $\mathrm{Fe}_{\text {base }}$ MMCs.

Increments in current density while increasing the sand content could be a consequence of the surface roughness generated by erosion (Ref 9), the generation of microstrain due to the mechanical deformation (Ref 14) and as presented in Fig. 8(a), changes in the $E_{\text {corr }}$ The more active values of the $E_{\text {corr }}$ indicate that as the sand concentration was periodically increased, the $\mathrm{Fe}_{\text {base }} \mathrm{MMCs}$ were energetically more prone to suffer corrosion attack.

At low sand content, the $\mathrm{Ni}_{\text {base }} \mathrm{MMCs}$ electrochemical response was entirely different under EC conditions as can be observed in Fig. 7(b) and 8(b). It was observed that below $0.5 \mathrm{~g} / \mathrm{L}$ the monitored current density did not show a considerable increase. It is a possibility that semi-protective Ni oxidehydroxides were formed on the surface of $\mathrm{Ni}_{\text {base }}$ MMCs which were not dramatically affected by erosion at contents below $0.5 \mathrm{~g} / \mathrm{L}$. For instance, Boudin et al. (Ref 46) studied the formation of semi-protective films on $\mathrm{Ni}$ alloys which retarded their anodic dissolution.

The aforementioned is supported by the fact that under solids-free conditions the $E_{\text {corr }}$ of the $\mathrm{Ni}_{\text {base }}$ MMCs became more negative and the potential was stabilized after approximately 20 min under EC conditions. In a previous study, Kear et al. (Ref 47) investigated the flow-influenced electrochemical corrosion of a nickel-aluminum-bronze alloy. They found that the flow dependence of $E_{\text {corr }}$ (more negative as the flow velocity was increased) was a consequence of a diffusioncontrolled process occurring on the surface of the alloy. The shift of the $E_{\text {corr }}$ of the $\mathrm{Ni}_{\text {base }}$ MMCs in the negative direction can be an indication of the formation of a semi-protective layer, which was severely damaged when the sand concentration was increased above $0.5 \mathrm{~g} / \mathrm{L}$. Consequently, it can be concluded that for the $\mathrm{Ni}_{\text {base }}$ MMCs at $0.5 \mathrm{~g} / \mathrm{L}$, there was a transition between a flow-induced corrosion to an EC process. In addition, above $3 \mathrm{~g} / \mathrm{L}$ the electrochemical response of the $\mathrm{Ni}_{\text {base }} \mathrm{MMCs}$ was not significantly affected by increments in sand contents.

For the $\mathrm{Fe}_{\text {base }} \mathrm{MMCs}$ a transition between flow-influenced corrosion to an EC process, such as that proposed for the $\mathrm{Ni}_{\text {base }}$ MMCs, was not identified since the monitored $i$ showed increments at all sand contents. Nevertheless, interesting observation can be made from analyzing Fig. 9(a). For instance, there was a significant and rapid increase of $i$ below

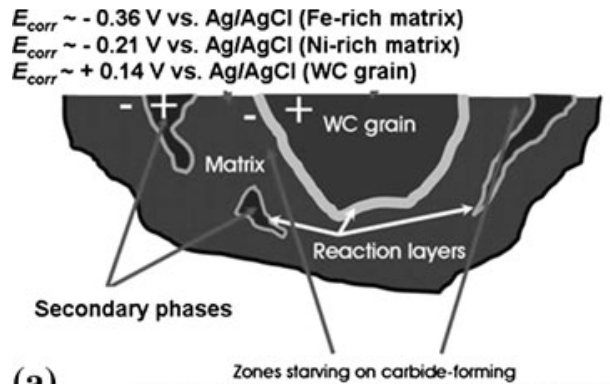

(a)

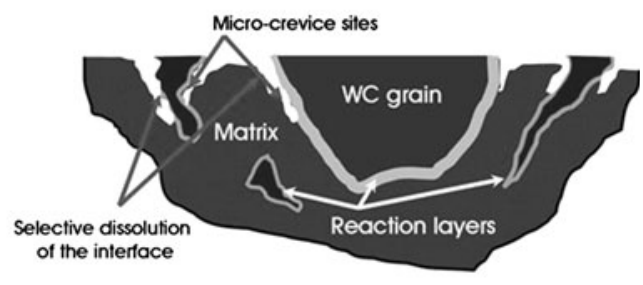

(b)

Fig. 10 Schematic representation of the corrosion mechanisms of the MMCs under static conditions 
$3 \mathrm{~g} / \mathrm{L}$ which was stabilized above that point and little changes in the $E_{\text {corr }}$ were observed at 10,25 , and $50 \mathrm{~g} / \mathrm{L}$ (Fig. 8a). Finally, above $3 \mathrm{~g} / \mathrm{L}$ a large area of the MMCs surface could be saturated by particle impacts and a further increase in the sand content, will not significantly affect the $\mathrm{Fe}_{\text {base }} \mathrm{MMCs}$ current response.

It is suggested in this article that above the breaking point, a large area of the MMC surface was subjected to sand particles impacts. For instance, assuming that all particles coming out of the nozzle reached the MMC surface, at $3 \mathrm{~g} / \mathrm{L}$ the surface is subjected to more than $1.2 \times 10^{5}$ impacts per second (impacts/s). Considering the number of impacts per second and the calculated area covered by every impact scar (Ref 26, 31), it was calculated that almost $30 \%$ of the MMC surface area could be saturated with impacts every second at $3 \mathrm{~g} / \mathrm{L}$. In addition, given that the matrix phase makes between 24 and $35 \%$ of the total MMC area, it is possible that the whole matrix (the phase susceptible to corrosion attack) was saturated with impacts. In terms of the impact scars and EC damage, it was previously reported by the authors (Ref 26, 31), that although the sand particle diameter was between 200 and $300 \mu \mathrm{m}$, the footprint (impact scar) produced by the impact was between 20 and $30 \mu \mathrm{m}$ size. Figure 11 shows a schematic representation of the impact footprint formed on the MMC surface as a consequence of a sand particle impact.

Considering the aforementioned, a further increase in sand content caused a greater mechanical damage and the MMCs electrochemical response is slightly affected. Indeed, the critical ranges of sand here proposed, are related to the effects of increasing sand content in the electrochemical response of the MMCs and are not necessarily linked the contribution of corrosion to the total EC damage. Although, the breaking point location and the current density response plateau (between 2 and $3 \mathrm{~g} / \mathrm{L}$, Fig. 9a) was material independent, the current density values monitored in the in situ potentiostatic tests were considerably higher for the $\mathrm{Fe}_{\text {base }} \mathrm{MMCs}$ compared with the $\mathrm{Ni}_{\text {base }} \mathrm{MMC}$. This can be explained given that the $\mathrm{Ni}_{\text {base }}$ MMCs (especially the WC-NiCrBSi MMC) showed lower $i$ values in the potentiostatic test (Fig. 2b) hence, slower charge transfer process. Therefore, it can be expected the monitored $i$

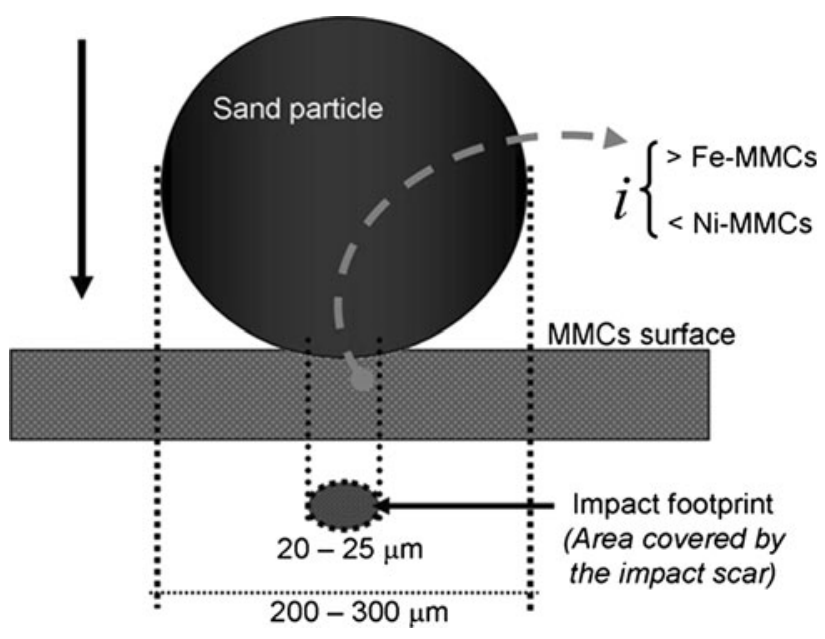

Fig. 11 Schematic representation of the impact footprint produced by a sand particle impacting the MMC matrix surface. In this figure, $i$ represents the current generated as a consequence of anodic dissolution of the damaged impacted area values from the eroded $\mathrm{Fe}_{\text {base }}$ MMCs surface to be higher than those showed by the eroded $\mathrm{Ni}_{\text {base }}$ MMC surface. Finally, when the corrosivity of the slurry was increased (solution at $65^{\circ} \mathrm{C}$ ) as observed in Fig. 9(b), although the current density was significantly higher than at $20^{\circ} \mathrm{C}$, the current density changes observed above $3 \mathrm{~g} / \mathrm{L}$ were also significantly smaller than those measured below.

\section{Conclusions}

1. The corrosion behavior and degradation mechanisms of the MMCs in static conditions were linked to the corrosion resistance of the matrix phase and the volume fraction of secondary phases embedded in the matrix. Changes in the slope of the Arrhenius plot and microscopic analysis suggested the existence of a transition zone from a more general corrosion process to a severe selective corrosion process which took place mainly at the interfacial zones.

2. Changes in the slope of the Arrhenius plot and microscopic analysis suggested the existence of a transition zone from a more general corrosion process (below regime I) to a severe selective corrosion process (regime II) which took place mainly at the interfacial zones and the eutectic.

3. Under EC conditions, the $\mathrm{Fe}_{\text {base }} \mathrm{MMCs}$ showed higher current density values compared to the $\mathrm{Ni}_{\text {base }} \mathrm{MMCs}$. For the $\mathrm{Ni}_{\text {base }} \mathrm{MMCs}$ below $0.5 \mathrm{~g} / \mathrm{L}$, sand content did not drastically affected their electrochemical response given the little change observed in the monitored current density. However, between 1 and $3 \mathrm{~g} / \mathrm{L}$ there was a significant and rapid increase of current which was stabilized above $3 \mathrm{~g} / \mathrm{L}$.

4. In order to reduce the partial dissolution of WC particles in the MMCs it is recommended to try Co- or Ni-coated WC particles which are now commercially available. If WC dissolution is reduced, it may help to reduce the concentration of $\mathrm{C}$ in the melted matrix prior to solidification therefore, the formation of a large volume fraction of secondary phases can be reduced.

\section{Acknowledgments}

Mr. J. F. Flores gratefully acknowledges the financial support of the European Union via Marie Curie Action, without which this work would not have been possible. The authors are also grateful for the materials and financial support provided by Syncrude Canada Ltd., Edmonton Research Centre, Edmonton, Alberta, Canada.

\section{References}

1. H.X. Guo, B.T. Lu, and J.L. Luo, Interaction of Mechanical and Electrochemical Factors in Erosion-Corrosion of Carbon Steel, Electrochim. Acta, 2005, 51(2), p 315-323

2. A. Neville, F. Reza, S. Chiovelli, and T. Revega, Assessing Metal Matrix Composites for Corrosion and Erosion-Corrosion Application in the Oilsands Industry, Corrosion, 2006, 62(8), p 657-675

3. J.F. Flores and A. Neville, Materials Selection in the Oilsands Industry Based on Materials Degradation Mechanisms, Explor. Prod. Oil Gas Rev., 2009, 7(1), p 42-45 
4. R. Llewellyn, Resisting Wear Attack in Oil Sands Mining and Processing, CIM Bull., 1997, 90(1012), p 75-82

5. B.R. Tian and Y.F. Cheng, Erosion-Corrosion of Hydrotransport Pipes in Oil Sand Slurries, Bull. Electrochem., 2006, 22(7), p 329-335

6. M. Schorr, B. Valdez, and J. de Dios Ocampo, Erosion-Corrosion in Industrial Steam Turbines, Mater. Perform., 2009, 48(9), p 62-65

7. M. Schorr, B. Valdez, and R. Zlatev, Erosion-Corrosion in Phosphoric Acid Production, Mater. Perform., 2010, 49(1), p 56-59

8. A.M.F. Carter, Erosion, Corrosion, and Abrasion of Material-Handling Systems in the Mining-Industry, J. S. Afr. Inst. Min. Metall., 1986, 86(7), p 235-242

9. F. Reza, "Corrosion and Erosion-Corrosion Behavior of Materials Used for Oilsands Applications," PhD Thesis, Herriot-Watt University, 2005

10. S. Das, D.P. Mondal, R. Dasgupta, and B.K. Prasad, Mechanisms of Material Removal During Erosion-Corrosion of an Al-SiC Particle Composite, Wear, 1999, 236(1-2), p 295-302

11. D. López, J.P. Congote, J.R. Cano, A. Toro, and A.P. Tschiptschin, Effect of Particle Velocity and Impact Angle on the Corrosion-Erosion of AISI, 304 and AISI, 420 Stainless Steels, Wear, 2005, 259(1-6), p $118-124$

12. I.M. Hutchings, Wear by Particulates, Chem. Eng. Sci., 1987, 42(4), p 869-878

13. G.L. Sheldon and I. Finnie, Mechanism of Material Removal in Erosive Cutting of Brittle Materials, J. Eng. Ind., 1966, 88(4), p 393

14. J. Xie, A.T. Alpas, and D.O. Northwood, The Role of Heat Treatment on the Erosion-Corrosion Behavior of AISI, 52100 Steel, Mater. Sci. Eng. A, 2005, 393(1-2), p 42-50

15. X. Hu and A. Neville, The Electrochemical Response of Stainless Steels in Liquid-Solid Impingement, Wear, 2005, 258(1-4), p 641-648

16. E.A.M. Hussain and M.J. Robinson, Erosion-Corrosion of 2205 Duplex Stainless Steel in Flowing Seawater Containing Sand Particles, Corros. Sci., 2007, 49(4), p 1737-1754

17. M.B. Abuzriba, R.A. Dodd, F.J. Worzala, and J.R. Conrad, Wear Corrosion-Separation of the Components of Corrosion and Wear, Corrosion, 1992, 48(1), p 2-4

18. N. Latona, P. Fetherston, A. Chen, K. Sridharan, and R.A. Dodd, WearCorrosion Comparisons of Passivating vs Nonpassivating Alloys in Aerated 3.5\% Aqueous Solutions of Sodium Chloride, Corrosion, 2001, 57(10), p 884-888

19. J.A. Bester and A. Ball, The Performance of Aluminium Alloys and Particulate Reinforced Aluminium Metal Matrix Composites in ErosiveCorrosive Slurry Environments, Wear, 1993, 162-164(Part 1), p 5763

20. K.P. Cooper, P.L. Slebodnick, K.E. Lucas, and E.A. Hogan, Microstructural Inhomogeneities and Sea Water Corrosion in LaserDeposited Ti-6Al-4V Alloy Matrix/Carbide Particulate Composite Surfaces, J. Mater. Sci., 1998, 33(15), p 3805-3816

21. W.S. Hwang and H.W. Kim, Galvanic Coupling Effect on Corrosion Behavior of Al Alloy-Matrix Composites, Met. Mater. Int., 2002, 8(6), p 571-575

22. E.J. Wentzel and C. Allen, The Erosion-Corrosion Resistance of Tungsten-Carbide Hard Metals, Int. J. Refract. Met. Hard Mater., 1997, 15(1-3), p 81-87

23. V.A. Souza and A. Neville, Corrosion and Erosion Damage Mechanisms During Erosion-Corrosion of WC-Co-Cr Cermet Coatings, Wear, 2003, 255(1-6), p 146-156

24. E.V. Skarb, D. Fix, D.V. Andreeva, H. Mohwald, and D.G. Shchukin, Surface-Modified Mesosporous $\mathrm{SiO}_{2}$ Containers for Corrosion Protection, Adv. Funct. Mater, 2009, 19(15), p 2373-2379

25. S. Zhou, M.M. Stack, and R.C. Newman, Characterization of Synergistic Effects Between Erosion and Corrosion in an Aqueous Environment Using Electrochemical Techniques, Corrosion, 1996, 52(12), p 934-946

26. J.F. Flores, A. Neville, N. Kapur, and A. Gnanavelu, An Experimental Study of the Erosion-Corrosion Behavior of Plasma Transferred Arc MMCs, Wear, 2009, 267(1-4), p 213-222
27. J.F. Flores, A. Neville, N. Kapur, and A. Gnanavelu, Erosion-Corrosion Degradation Mechanisms of Fe-Cr-C and WC-Fe-Cr-C PTA Overlays in Concentrated Slurries, Wear, 2009, 267(11), p 1811-1820

28. "Standard Practice for Conventions Applicable to Electrochemical Measurements in Corrosion Testing," ASTM G3-89, Vol 3(2), 2004

29. "Standard Reference Test Method for Making Potentiostatic and Potentiodynamic Anodic Polarization Measurements," ASTM G5-94, Vol 3(2), 2004

30. J.B. Zu, I.M. Hutchings, and G.T. Burstein, Design of a Slurry Erosion Test Rig, Wear, 1990, 140(2), p 331-344

31. J.F. Flores, Corrosion and Erosion-Corrosion Processes of Metal Matrix Composites in Slurry Conditions for Oilsands Applications, $\mathrm{PhD}$ Thesis, University of Leeds, 2010, p 101-110

32. J.E. House, Principles of Chemical Kinetics, 2nd ed., Academic Press, New York, 2007

33. S.R. Dharwadkar, A.B. Phadnis, M.S. Chandrasekharaiah, and M.D. Karkhanavala, A Simple Method of Determining the Activation Energy of an Isothermal Solid-State Decomposition Reaction, J. Therm. Anal. Calorim., 1980, 18(1), p 185-191

34. J.F. Flores, A. Neville, N. Kapur, and A. Gnanavelu, Erosion-Corrosion Performance of Plasma Transferred Arc Overlays in Slurry Conditions, Proceedings Corrosion International Conference (CORROSION/ 2009), Paper No. 09482, Atlanta, GA

35. S. Babu, S. David, R. Martukanitz, and K. Parks, Toward Prediction of Microstructural Evolution During Laser Surface Alloying, Metall. Mater. Trans. A, 2002, 33(4), p 1189-1200

36. A. VandeRunstraat, J. VanGrondelle, and R.A. VanSanten, On the Temperature Dependence of the Arrhenius Activation Energy for Hydroisomerization Catalyzed by Pt/Mordenite, J. Catal., 1997, 167(2), p 460-463

37. J.S. Charnock, D.A. Cook, and R. Casey, The Role of Cations and Other Factors on the Apparent Energy of Activation of $(\mathrm{Na}++\mathrm{K}+)$ ATPase, Arch. Biochem. Biophys., 1971, 147(1), p 323-329

38. L.B. Kriksunov and D.B. Macdonald, Corrosion in Supercritical Water Oxidation Systems: A Phenomenological Analysis, J. Electrochem. Soc., 1995, 142(12), p 4069-4073

39. M.A. Pagano and S.B. Lalvani, Corrosion of Mild-Steel Subjected to Alternating Voltages in Seawater, Corros. Sci., 1994, 36(1), p 127-140

40. J.P. Popic and D.M. Drazic, Electrochemistry of Active Chromium. Part III. Effects of Temperature, J. Serb. Chem. Soc., 2003, 68(11), p $871-881$

41. J.P. Cai and S.B. Lyon, A Mechanistic Study of Initial Atmospheric Corrosion Kinetics Using Electrical Resistance Sensors, Corros. Sci., 2005, 47(12), p 2956-2973

42. V.P. Grigorev, V.M. Kravchenko, and I.M. Gershanova, Apparent Activation Energy of the Anodic Dissolution of Nickel in Sulfuric Acid Solutions in the Presence of $\mathrm{Cl}-$ and CNS- Ions, Prot. Met., 2004, 40(3), p 214-219

43. S. Sutthiruangwong and G. Mori, Corrosion Properties of Co-Based Cemented Carbides in Acidic Solutions, Int. J. Refract. Met. Hard Mater, 2009, 21(3-4), p 135-145

44. A. Neville, F. Reza, S. Chiovelli, and T. Revega, Characterization and Corrosion Behavior of High-Chromium White Cast Irons, Metall. Mater. Trans. A, 2006, 37(8), p 2339-2347

45. A.F. Zhang, J.D. Xing, L. Fang, and J.Y. Su, Inter-Phase Corrosion of Chromium White Cast Irons in Dynamic State, Wear, 2004, 257(1-2), p 198-204

46. S. Boudin, J.-L. Vignes, G. Lorang, M. Da Cunha Belo, G. Blondiaux, S.M. Mikhailou, J.P. Jacobs, and H.H. Brongersma, Analytical and Electrochemical Study of Passive Films Formed on Nickel-Chromium Alloys: Influence of the Chromium Bulk Concentration, Surf. Interface Anal., 1994, 22(1-12), p 462-466

47. G. Kear, B.D. Barker, K. Stokes, and F.C. Walsh, Flow Influenced Electrochemical Corrosion of Nickel Aluminium Bronze-Part II. Anodic Polarisation and Derivation of the Mixed Potential, J. Appl. Electrochem., 2004, 34(12), p 1241-1248 